\title{
Complications of Airway Management
}

\author{
Paulette C Pacheco-Lopez MD, Lauren C Berkow MD, \\ Alexander T Hillel MD, and Lee M Akst MD \\ Introduction \\ Methods \\ Results \\ Risk Factors \\ Injury by Anatomic Site \\ Late Complications of Intubation \\ Special Considerations \\ Conclusion
}

\begin{abstract}
Although endotracheal intubation is commonly performed in the hospital setting, it is not without risk. In this article, we review the impact of endotracheal intubation on airway injury by describing the acute and long-term sequelae of each of the most commonly injured anatomic sites along the respiratory tract, including the nasal cavity, oral cavity, oropharynx, larynx, and trachea. Injuries covered include nasoseptal injury, tongue injury, dental injury, mucosal lacerations, vocal cord immobility, and laryngotracheal stenosis, as well as tracheomalacia, tracheoinnominate, and tracheoesophageal fistulas. We discuss the proposed mechanisms of tissue damage that relate to each and present their most common clinical manifestations, along with their respective diagnostic and management options. This article also includes a review of complications of airway management pertaining to video laryngoscopy and supraglottic airway devices. Finally, potential strategies to prevent intubation-associated injuries are outlined. Key words: intubation; airway complications; subglottic stenosis; vocal cord injury [Respir Care 2014;59(6):1006-1021. () 2014 Daedalus Enterprises]
\end{abstract}

\section{Introduction}

The establishment of an adequate airway is integral to managing patients both in the elective operating room setting and in the emergent nonoperating room setting. Endotracheal intubation is a basic skill performed daily by

Drs Pacheco-Lopez, Hillel, and Akst are affiliated with the Department of Otolaryngology, and Dr Berkow is affiliated with the Department of Anesthesia, Johns Hopkins University School of Medicine, Baltimore, Maryland.

Dr Berkow presented a version of this paper at the 52nd RESPIRATORY CARE Journal Conference, "Adult Artificial Airways and Airway Adjuncts," held June 14 and 15, 2013, in St Petersburg, Florida.

The authors have disclosed no conflicts of interest.

Correspondence: Lauren C Berkow MD, Department of Anesthesia, Johns Hopkins University School of Medicine, Phipps 404, 600 North Wolfe Street, Baltimore, MD 21287. E-mail: lberkow1@jhmi.edu.

DOI: $10.4187 /$ respcare.02884 health care professionals throughout the world and is a relatively safe maneuver. However, endotracheal intubation is not risk-free, and its complications are well described in the literature. These can range from minor soft tissue injuries to severe, long-term, life-threatening airway complications.

The incidence of airway injury caused by endotracheal intubation ranges from 0.5 to $7 \% .^{1}$ Such injuries can occur at the initiation of intubation or can develop as a result of prolonged intubation. According to a closed-claims analysis by Domino et al. ${ }^{2} 6 \%$ of claims against anesthesiology providers were for airway injury, with the larynx being the most common site of injury, followed by the pharynx and the esophagus. Data from England documented by Cook et $\mathrm{al}^{3}$ demonstrate a similar percentage of claims related to airway management (8\%). Beyond medicolegal issues, intubation-related injury is also a significant financial burden. Patients with intubation-related injuries increased hospital costs by $20 \%$, and stay was $1 \mathrm{~d}$ longer than it was for matched patients without intubation injury. 
In addition, repeated admissions were more frequent in the injured cohort. ${ }^{4}$

This review article will discuss several types of airway complications from endotracheal intubation. Some injuries, such as soft tissue hematomas, lacerations, and arytenoid dislocation, may result from the initial act of intubation. Other injuries, such as laryngotracheal stenosis and vocal fold paralysis, may result from tissue-endotracheal tube (ETT) interactions, even if intubation was performed without direct tissue trauma. We will review both categories of injury and focus on risk factors, pathogenesis, presentation, and management of some of the most commonly seen complications.

\section{Methods}

We carried out a systematic search of the PubMed database. A broad search was used so as to augment the citations of peer-reviewed journals regarding airway complications in endotracheal intubation. The Medical Subject Headings used in the search were: airway, oral cavity, oropharyngeal, laryngeal, subglottic, and tracheal complications AND endotracheal or nasotracheal intubation, GlideScope, or laryngeal airway mask. The searches were repeated in combination with epidemiology, pathophysiology, and treatment. In addition, we carried out manual searches within the references of pertinent articles. The search was limited to articles published in the English language, but no date restrictions were applied.

\section{Results}

\section{Risk Factors}

In attempts to diminish morbidity and to improve patient care, many have sought to define the risk factors for airway injury during endotracheal intubation. As might be expected, intubations categorized as difficult pose a higher risk of injury than do those that are not difficult. Nevertheless, $39 \%$ of airway injuries described in a closed-claims analysis were associated with difficult emergent intubations, even though the incidence of difficult intubation among patients undergoing elective surgery has been reported to be only 5.8\%. ${ }^{5}$ However, the incidence of difficult intubation is higher in the emergent setting compared with elective procedures (8-12 vs 6\%). ${ }^{1}$ Emergent airway management often requires physicians to intervene urgently, without adequate time to obtain a thorough patient history. Patients are also more likely to be hemodynamically unstable, a condition that might contribute to the complexity of intubation in this setting.

The skill level of the provider who performs the intubation has also been studied as a potential risk factor for airway complications. Skill level inversely correlates with number of attempts at laryngoscopy, with higher skill levels correlating with fewer attempts, and repeated laryngoscopy attempts may lead to tissue trauma, edema, and bleeding. ${ }^{1}$ Indeed, complications increase 7 -fold after the second and third laryngoscopy attempts. ${ }^{6}$ Patients of junior residents have complication rates ranging from 4 to $9 \%$ in emergent situations, whereas those of senior residents have only a $2.3 \%$ complication rate. ${ }^{1,7-9}$ Attending supervision during emergent intubation also appears to lower complication rates significantly ( 6 vs $21 \%, P<.001) .{ }^{8}$ Schmidt et $\mathrm{a}^{8}$ stated that attending supervision of emergent intubations occurred more frequently in the ICU than in the wards and that patients in the ICU were more likely to receive muscle relaxants for intubation. The role of attending supervision has been the source of much debate because the mere presence of a second anesthesia provider, regardless of experience level, may facilitate intubation..$^{10}$ Therefore, it is unclear whether the decrease in complication rate results from the additional help provided by a second anesthesiologist or relates specifically to the level of training of the provider performing the intubation.

Patient factors also influence the degree and severity of airway complications after endotracheal intubation. Some systemic conditions can predispose patients to develop major complications from the physiologic insult of intubation. These factors are being investigated, but it remains unclear why some patients develop long-term sequelae, whereas others exposed to the same mechanisms of injury do not. There appears to be a trend toward a higher incidence of airway injury in patients with diabetes mellitus, hypertension, hypotension, heart disease, kidney or liver failure, and malnutrition. ${ }^{11,12}$ It is believed that these disease states may lead to poor tissue perfusion, with implications for wound healing, necrosis, and ulceration..$^{12,13}$ Likewise, laryngopharyngeal reflux has also been implicated as a risk factor. ${ }^{14}$ Laryngopharyngeal reflux may cause airway injury in critically ill patients because gastric acid can spill over the larynx and expose tissues to pepsin, exacerbating local injury, delaying wound healing, and predisposing the patient to infection. ${ }^{12}$

The roles that patient age and gender might play in complications of endotracheal intubation are unclear, with studies arguing both for and against their impact. Kikura et $\mathrm{al}^{11}$ found that patients who were $\geq 50 \mathrm{y}$ old had 3 times the risk of younger patients for developing vocal cord paralysis. Female gender also has been suggested as a risk factor for developing postextubation laryngeal edema and subglottic stenosis. ${ }^{15-17}$ It has been speculated that the laryngotracheal mucosa in men may be more resilient to trauma than that in women and that the dimensions of the larynx and trachea are smaller in women than in men, making them more prone to injury, especially if an inadequately sized tube is used. ${ }^{18,19}$ Other studies have found no correlation between laryngeal injury or vocal fold im- 
mobility after controlling for age, gender, height, and weight. ${ }^{20}$

Obesity as a predictor of the difficult airway has been well studied, and specific challenges are known to be inherent to intubation of obese patients. ${ }^{21-23}$ Obese patients may have crowding and distortion of the oropharynx, limited neck extension, a higher incidence of comorbid conditions, and a lower tolerance for apnea and tissue hypoxia. ${ }^{21,23,24}$ Holmberg et al ${ }^{21}$ observed that class I/II obesity (body mass index $>30 \mathrm{~kg} / \mathrm{m}^{2}$ and $<40 \mathrm{~kg} / \mathrm{m}^{2}$ ) in patients was not associated with difficult intubation, whereas patients with body mass index $>40 \mathrm{~kg} / \mathrm{m}^{2}$ had higher rates of difficult intubation. Despite the relationship between obesity and difficult intubation, however, it remains unclear whether obesity is a risk factor for complications from intubation. Colton House et $\mathrm{al}^{20}$ found that weight does not appear to have a significant correlation with the incidence of laryngeal injury. Likewise, Dargin et a ${ }^{25}$ concluded that body mass index was not predictive of postintubation complications. Interestingly, they also found that obesity, but not morbid obesity, predicted difficult intubation. Currently, the relationships between obesity, difficult intubation, and intubation-related injury remain uncertain.

\section{Injury by Anatomic Site}

Nasal Cavity. Nasotracheal intubation is a common alternative to orotracheal intubation in patients for whom surgical access to the oral cavity is necessary, such as in some head-and-neck, otolaryngology, or maxillofacial surgery cases. Nasotracheal intubation may also be the preferred method of intubation in patients with trismus. The incidence of epistaxis during nasotracheal intubation ranges from 29 to $96 \% .{ }^{26-28}$ Epistaxis may result from soft tissue injury, such as mucosal abrasions, tears, or lacerations. Self-limited epistaxis is the most common presentation of minor soft tissue injury to the nasal mucosa. More serious injuries should be considered if blood pools in the oral cavity. Life-threatening blood loss from epistaxis has also been reported. ${ }^{29}$ If blood remains trapped deep in mucosal surfaces within the nose, hematomas may result, leading to concern for devascularization of underlying cartilage and subsequent structural deformity.

Investigators have compared intubation of the right and left nostrils to determine whether laterality poses a difference in complication rates. Coe and Human ${ }^{30}$ found no significant difference in bleeding based on nostril side. Sanuki et al $^{31}$ documented the left nostril as being more prone to severe epistaxis ( $22 \%$ (left) vs $0 \%$ (right), $P<.02$ ). The left side might be injured more frequently because the beveled tip of the ETT faces the left side and impacts the more vascular mucosa of the turbinates. ${ }^{32}$ The most common injury is bruising at the septum or inferior turbinate. ${ }^{26,27}$ However, forceful nasotracheal intubations can also cause inadvertent injury to the lateral nasal wall, causing accidental avulsion of the turbinates ${ }^{33-35}$ and posterior pharyngeal lacerations. ${ }^{36,37}$

Although generally considered a temporary mode of intubation, some patients require prolonged intubation via the nasotracheal route. Long-term injury can be related to malpositioning of the tube against the nasal alae, causing ischemia, ulceration, and ultimately pressure necrosis of the alar tissue. In addition, prolonged nasotracheal intubation has been associated with sinusitis, which can develop when the ETT obstructs maxillary sinus drainage. ${ }^{38}$ However, other studies have documented no significant difference in the incidence of sinusitis between patients who have prolonged orotracheal intubation and those who have prolonged nasotracheal intubation. ${ }^{39}$

Preoperative nasal endoscopy and digital manipulation may be used to determine the most patent nostril in an effort to limit complications from nasotracheal intubation. In addition, ample use of lubricants; nasal decongestion with cocaine, epinephrine, or oxymetazoline; and warming of the tube may be used to facilitate tube passage. ${ }^{40,41}$ The management of nasotracheal injury depends on its severity. Mucosal abrasions, tears, and hematomas usually resolve with conservative management, such as nasal humidification and nasal pressure. Large septal hematomas can cause concern for potential septal perforation, as dissection of the mucoperichondrium from the underlying cartilage may compromise vascular supply. If large septal hematomas are identified, otolaryngology consultation for management and drainage is recommended. ${ }^{42,43}$ Other forms of injury, such as turbinate avulsion, might also require otolaryngology evaluation to determine the need for nasal packing or cauterization of the mucosa if bleeding persists. Pharyngeal lacerations may heal without significant sequelae, but in these cases, one should watch vigilantly for the development of retropharyngeal hematomas or abscesses that may lead to airway compromise. Pressure sores of the nasal alae may be managed with local care unless significant necrosis has led to loss of tissue and cosmetic deformity. Such defects require plastic reconstruction.

Oral Cavity and Oropharynx. Dental injury during laryngoscopy is one of the most common complaints against anesthesiologists. ${ }^{44,45}$ These types of injuries are often due to pressure on the maxillary incisors, which anesthesiologists sometimes use as a fulcrum for the laryngoscope while attempting to visualize the larynx. Laryngoscopy may also cause inadvertent soft tissue injury to the lips, buccal mucosa, floor of mouth, palate, and tongue. These injuries can also be caused by the insertion of ETTs, orogastric tubes, temperature probes, and oral airways. The mechanism of injury is direct tissue trauma from the offending medical device. Oral cavity injury should be sus- 
pected in the presence of mucosal discoloration and hematoma formation, blood-tinged secretions, or oozing of blood from scraped or lacerated surfaces during suctioning. The severity of injury ranges from minor hematomas and mucosal lacerations that heal spontaneously to larger soft tissue defects that may require primary repair with suture. Mediastinitis and internal carotid thrombosis have also been described after oropharyngeal perforations, but these are exceedingly rare..$^{46,47}$

\section{Larynx}

Hoarseness. Ninety-seven percent of intubations, even for very brief periods, may lead to some form of laryngeal injury. ${ }^{12,48,49}$ Injuries may include vocal cord erythema, ulcers, granulomas, and, less commonly, vocal cord immobility. ${ }^{48}$ After being extubated, many patients have transient complaints of vocal fatigue, dysphagia, sore throat, hoarseness, throat clearing, and aspiration. Hamdan et al ${ }^{50}$ studied the short-term effects of intubation on voice and found that the most important variables associated with an increase in vocal symptoms were mean cuff pressure and volume. Patients with persistent vocal fatigue had higher mean cuff volumes than did patients without that symptom, and persistent throat clearing was more prevalent in patients with higher mean cuff pressures. ${ }^{50}$ However, Hamdan et al ${ }^{50}$ also documented that most of these symptoms resolved within $24 \mathrm{~h}$. When symptoms persist or progress, the presence of more serious injuries, such as vocal fold lacerations, hematomas, or avulsion, must be considered because these injuries usually take longer to heal and could potentially lead to poor voice outcomes, prolonged voice problems, and vocal fold scarring. ${ }^{51}$ In a survey of patients regarding postintubation dysphonia, $49 \%$ of patients stated that they had vocal difficulty on the day of surgery, but the symptoms improved over time, with 29,11 , and $0.8 \%$ stating that dysphonia was present on postoperative days 1,3 , and 7 , respectively. ${ }^{52}$ It is estimated that $1 \%$ of patients may continue to experience dysphonia related to chronic injury of the vocal folds after acute and subacute healing are complete. ${ }^{11}$

Vocal Cord Paralysis. Patients may develop vocal fold paralysis secondary to short-term or long-term intubation. ${ }^{12}$ This is an exceedingly rare injury and is thought to occur in only $0.033-0.07 \%$ of intubations. ${ }^{11,53}$ When viewed as a proportion of cases of vocal cord paralysis rather than as a percentage of intubations, vocal fold paralysis related to intubation injury seems more common. Intubation is estimated to be the cause of paralysis in $4-7.5 \%$ of cases of unilateral vocal fold immobility and $9-25 \%$ of cases of bilateral vocal fold immobility. ${ }^{54,55}$ To put these numbers into perspective, iatrogenic injury to the recurrent laryngeal nerves during surgery (such as carotid endarterecto- mies, anterior approaches to the cervical spine, and thyroid surgeries) accounts for the largest proportion of vocal fold immobility cases $(23.9-56 \%) .{ }^{54}$

Several theories have been put forth to explain the pathogenesis of recurrent laryngeal nerve paralysis after endotracheal intubation. The recurrent laryngeal nerve runs in the trachea-esophageal groove lateral to the cricoid cartilage; its internal branch then enters the larynx between the cricoid and thyroid cartilages near the cricoarytenoid joint. Its endolaryngeal segment is especially vulnerable to compression between an ETT cuff and the internal thyroid lamina, particularly if the cuff sits too high and if the cuff pressures exceed capillary perfusion pressure. This compression may compromise vascularity and result in nerve dysfunction. ${ }^{53,56,57}$ Awareness of maintaining appropriate cuff pressures is widespread. However, recent reports have documented that cuff pressures may increase from baseline values when cervical retractors are positioned for exposure during anterior cervical spine surgery. ${ }^{58,59}$ In addition, cadaver studies performed by Kriskovich et al ${ }^{59}$ confirmed that cervical retractors may displace the larynx against the shaft of the ETT with impingement on the vulnerable intralaryngeal segment of the recurrent laryngeal nerve. The authors proposed that deflating the cuff after retractors have been positioned enables the tube to migrate inferiorly and diminishes the incidence of paralysis. ${ }^{59}$ However, a similar study by Audu et al ${ }^{60}$ documented that although cuff deflation/inflation decreased ETT cuff pressure, it did not reduce the incidence of vocal fold immobility (15.4 vs $14.5 \%)$. Stretching of the nerve during tube manipulation or intubation has also been proposed as a mechanism of injury. ${ }^{61}$

Symptoms of vocal fold immobility include acute onset of weak breathy voice and increased vocal effort. Occasionally, dysphonia related to vocal fold immobility is also associated with dysphagia and increased aspiration risk. When unilateral vocal fold immobility is suspected, otolaryngology examination with visualization of the larynx can confirm the diagnosis. Physical examination should include a complete head-and-neck exam and assessment for other cranial nerve injuries. Flexible or mirror laryngoscopy is also essential for assessment of mobility. A paralyzed vocal fold is usually found in the paramedian position $(75 \%)$ and is less often in the lateral $(13 \%)$ or midline (11.3\%) position (Fig. 1). ${ }^{62}$ The position of paralysis was once believed to depend on whether the superior laryngeal nerve was injured, causing the vocal fold to lie in a more lateral position. However, subsequent studies have shown that the superior laryngeal nerve and hence cricothyroid muscle function do not predict vocal cord position. Rather, the position of paralysis depends on the degree of reinnervation and synkinesis present. ${ }^{63-65}$ When some adductor motion is present on laryngoscopy, it should not be confused with mobility. Instead, this motion may be caused by contralateral innervation of the interarytenoid 


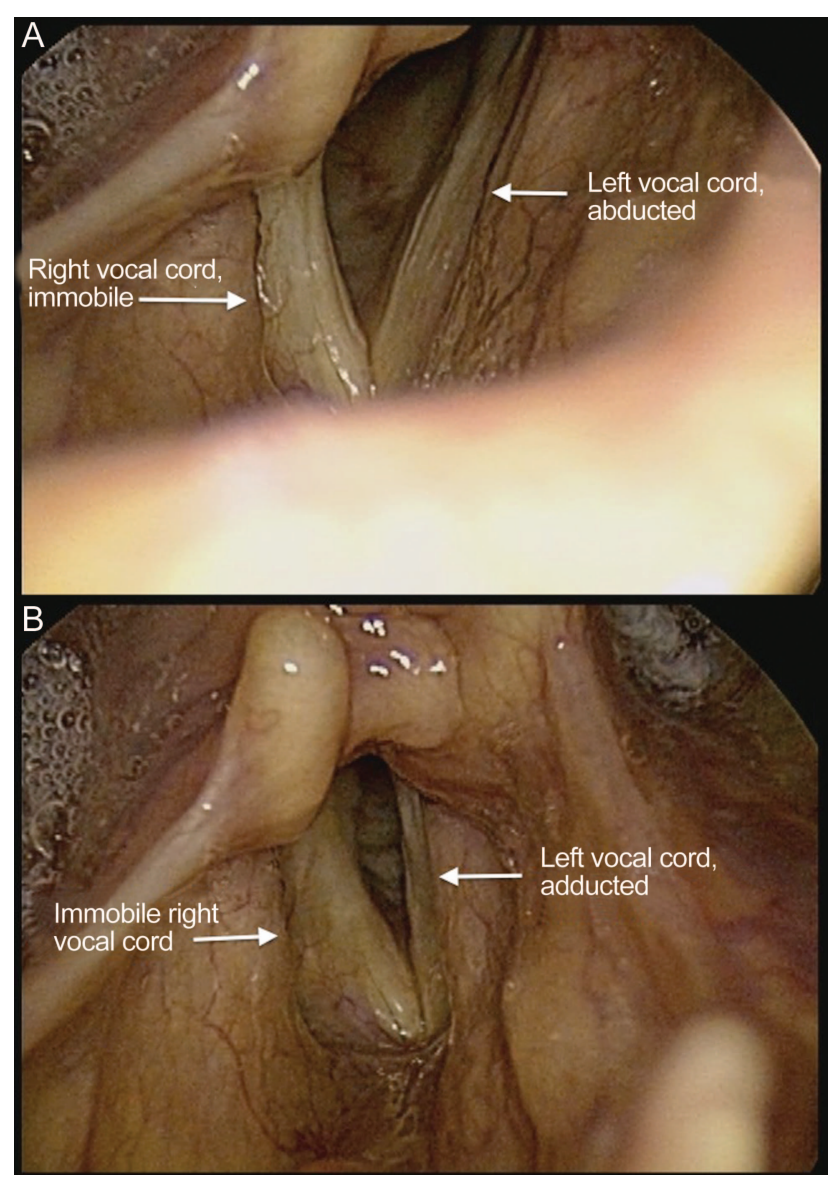

Fig. 1. A: Right vocal cord paralysis, abduction. Note bowing and loss of tone on the right versus the left side. There is asymmetry in the position of the arytenoids during full abduction. The right arytenoid is anteriorly rotated, while the left moves posterolaterally during inspiration. B: Right vocal cord paralysis, adduction. Note bowing and loss of tone of the right vocal cord. There is a glottal gap on full adduction, as well as left compensatory false vocal fold compression that obstructs the view of the left true vocal cord.

muscle, which contributes to vocal cord adduction bilaterally. ${ }^{65}$ Atrophy and bowing of the paralyzed cord and anterior rotation of the arytenoid are also common findings. Stroboscopy may show evidence of height mismatching and a diminished, asymmetric, or absent mucosal wave when the vocal cord lies in the paramedian or lateral position. ${ }^{66}$ This position significantly compromises glottal competence and phonation, thus worsening patient symptoms. Left immobility is more common than right immobility, perhaps because most intubations are performed from the right side using the right hand. Therefore, the tube tends to rest toward the right side proximally, and toward the left side distally. ${ }^{12,20,54,55}$

Patients may recover spontaneously when recurrent laryngeal nerve continuity has been preserved. If no motion is appreciated within 6-12 months and/or electromyography shows signs of denervation, recovery is unlikely. Midline unilateral paralysis rarely requires intervention. However, patients who have glottic insufficiency related to a paramedian or lateral position of the paralyzed vocal fold may benefit from medialization of the immobile vocal fold to the midline so that glottic closure is improved. Techniques for medialization include vocal fold injection, laryngeal framework surgery, and arytenoid adduction procedures; these techniques can re-establish glottal competence, strengthen the voice, and improve swallowing safety. If it is unknown whether paralysis is temporary or permanent, temporary injection augmentations can support voice and swallowing while the patient awaits potential recovery. Although studies are sparse, limited information suggests that $35 \%$ of patients with unilateral vocal fold paralysis will experience recovery without need for subsequent intervention. ${ }^{67}$

Arytenoid Dislocation and Subluxation. Unilateral vocal cord immobility related to intubation can also occur as a result of mechanical fixation of the cricoarytenoid joint, rather than as a consequence of recurrent laryngeal nerve injury. As it relates to intubation, the possibility that mechanical loss of vocal fold motion may be caused by direct trauma to the arytenoid cartilage itself is controversial. In this context, arytenoid dislocation refers to complete loss of contact between the cricoid and arytenoid cartilages, and subluxation refers to only partial loss of contact. $^{68}$ Vocal fold immobility secondary to arytenoid dislocation is considered rare, and some specialists do not think that true arytenoid dislocation is possible on an anatomic basis. ${ }^{69}$ Unfortunately, true incidence rates of arytenoid dislocation or subluxation are unclear because unilateral vocal fold immobility may be attributed to neurogenic vocal fold paralysis rather than mechanical fixation. Physical examination can sometimes offer insight into the differential diagnosis between neurogenic paralysis and joint fixation: faint twitches of motion suggest a mobile joint, whereas complete immobility and a malrotated arytenoid might instead suggest mechanical issues, such as arytenoid subluxation. Electromyography and joint palpation with the patient under general anesthesia can also be used to distinguish between mechanical and neurogenic causes of vocal fold immobility.

Using histologic studies, Paulsen et $\mathrm{al}^{70}$ found that the cricoarytenoid joint contains large synovial folds that are vulnerable to trauma by forceful intubation. Trauma to these folds can potentially lead to hemarthrosis, joint adhesion, and fixation of the arytenoid in an abnormal position. ${ }^{70}$ The most common cause of arytenoid dislocation and subluxation is thought to be intubation trauma, with posterior dislocation being more common than anterior dislocation. ${ }^{71}$ The proposed mechanism of injury for anterior arytenoid dislocation is described in the literature as direct forward pressure on the posterior arytenoid, either by the laryngoscope used for intubation or by the ETT 


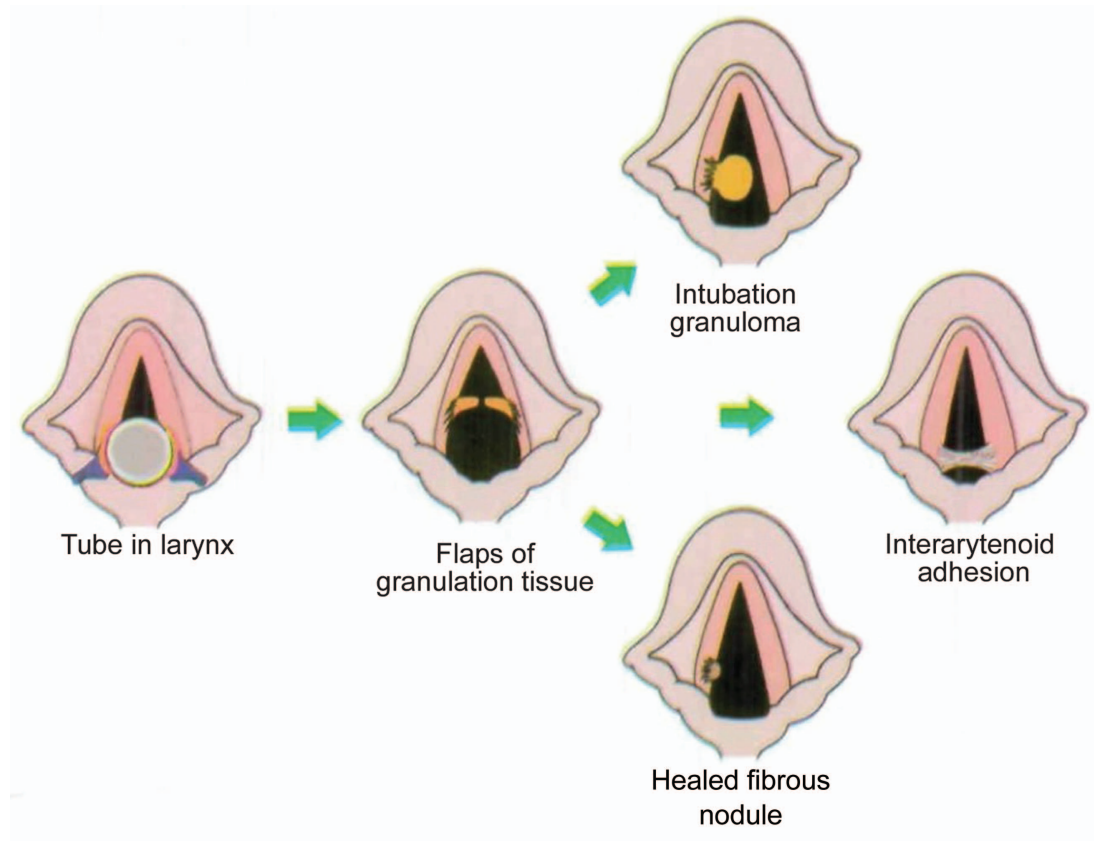

Fig. 2. Diagram chart of possible outcomes of ulceration, namely, intubation granuloma, interarytenoid adhesion, and healed fibrous nodule. From Reference 12, with permission.

itself pushing the arytenoid anteriorly off the cricoid facet. Posterior dislocation is believed to occur during extubation, perhaps during removal of an incompletely deflated cuff. ${ }^{72}$ Despite the alleged mechanisms of possible arytenoid dislocation, the very existence of the entity remains controversial. Some authors suggest that traumatic dislocation is impossible. Attempts at purposeful dislocation in cadaveric larynges have been unsuccessful because the laryngeal musculature preserves the integrity of the saddle joint relationship of the cricoid and arytenoid cartilages. ${ }^{69,73}$

The clinical symptoms of patients with cricoarytenoid dislocation are similar to those of patients with true vocal cord paralysis, with hoarseness, breathiness, and vocal fatigue being the most common. Direct laryngoscopy of patients under general anesthesia can be an important step to help differentiate between arytenoid fixation or dislocation and neurogenic paralysis, as joint palpation allows for assessment of passive joint mobility. ${ }^{65}$ The same otolaryngologic direct laryngoscopy that allows for arytenoid palpation to differentiate between neurogenic paralysis and mechanical fixation also provides a therapeutic option for patients with suspected dislocation, as endoscopic reduction can be performed immediately upon diagnosis. Despite the controversial nature of the very existence of true arytenoid dislocation, recent reports document that closed reductions can provide satisfactory improvements in voice even after late surgical intervention. $62,71,74$

\section{Late Complications of Intubation}

Laryngotracheal Stenosis. In contrast to many of the injuries discussed thus far, which occur acutely during intubation or after a short period of intubation, laryngotracheal stenosis can be a long-term consequence of prolonged intubation. In fact, the most common cause of adult laryngotracheal stenosis is endotracheal intubation. ${ }^{75,76}$ The duration of intubation has been found to correlate significantly with the incidence of laryngeal pathologies, including the development of subglottic edema and narrowing when intubation time exceeds 7 d. ${ }^{16,77}$ However, Colton House et $\mathrm{al}^{20}$ demonstrated no significant difference in the development of subglottic edema regardless of duration of intubation or tube size. The presence of comorbidities, such as diabetes mellitus, gastroesophageal reflux, and immunosuppression, have also been shown to predispose patients to develop stenosis. ${ }^{17,20,78,79}$ Therefore, this population would perhaps benefit from early tracheotomy. ${ }^{78}$

The reported historical incidence of laryngotracheal stenosis after endotracheal intubation ranges from 1 to $21 \%, 76,80$ but it is hoped that increasing knowledge about how to limit airway injury from prolonged intubation will reduce these rates. Inflammatory changes in the posterior glottis can be seen as early as $2-5 \mathrm{~d}$ after intubation. ${ }^{77} \mathrm{~A}$ widely accepted mechanism of injury is localized tissue ischemia that occurs when the pressure exerted by the ETT 


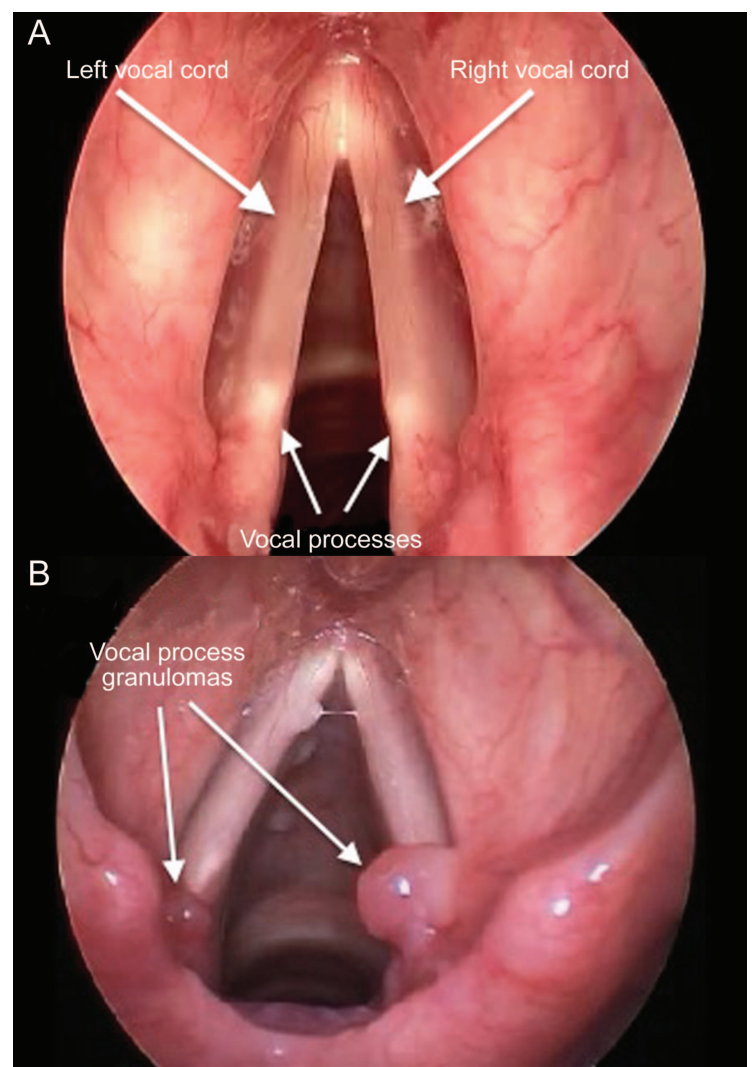

Fig. 3. A: Operative view of a normal glottis. B: Bilateral vocal process granulomas.

exceeds tissue capillary pressure. The excessive pressure can lead to vascular damage and formation of edema, granulation, and ulcers. ${ }^{12}$ The most common sites at the level of the larynx are the posterior glottis and interarytenoid regions, where the ETT rests. The progression to scar tissue has been described by Benjamin and Holinger ${ }^{12}$ as a continuum of disease that begins with localized tissue ischemia that results from compression by the ETT and progresses to necrosis and ulcer formation, especially at areas of exposed perichondrium, such as the vocal processes (Fig. 2). The reparative process continues with the formation of granulation tissue, a hallmark of wound healing, which involves neovascularization as well as proliferation of inflammatory cells and fibroblasts (Fig. 3). As the granulomas mature and proliferate, deposition of collagen eventually leads to scar formation and tissue contracture. ${ }^{12}$ Stenosis may occur at any subsite where tissues are in contact with the ETT or cuff, namely the posterior glottis, subglottis, and proximal trachea (Figs. 4 and 5). Injuries may span more than one level in $25 \%$ of cases, as documented by Anand et al. ${ }^{80}$

Scarring and fibrosis in the interarytenoid or posterior glottic region impair adequate vocal cord abduction bilaterally and may resemble bilateral vocal cord paralysis (Fig. 5). Failure to adequately abduct with inspiration can com-

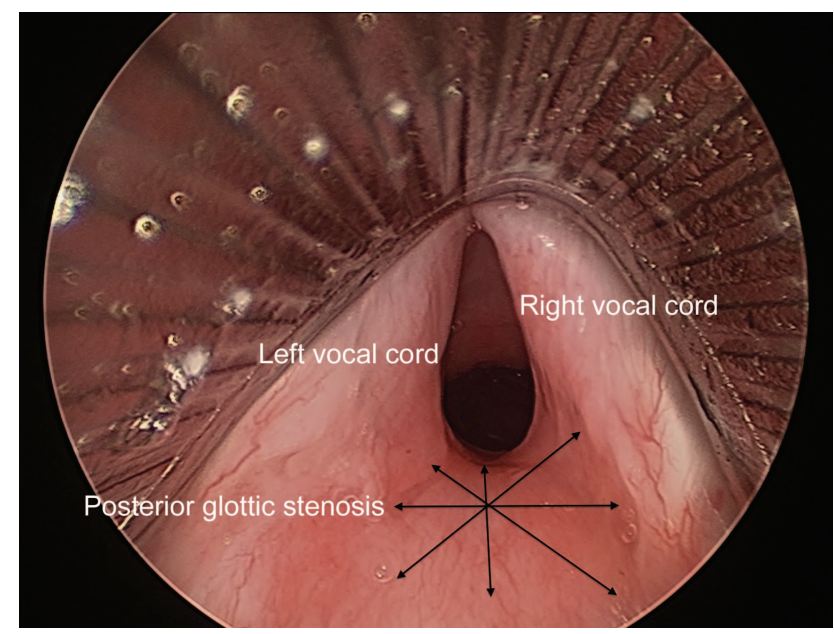

Fig. 4. Posterior glottic stenosis.

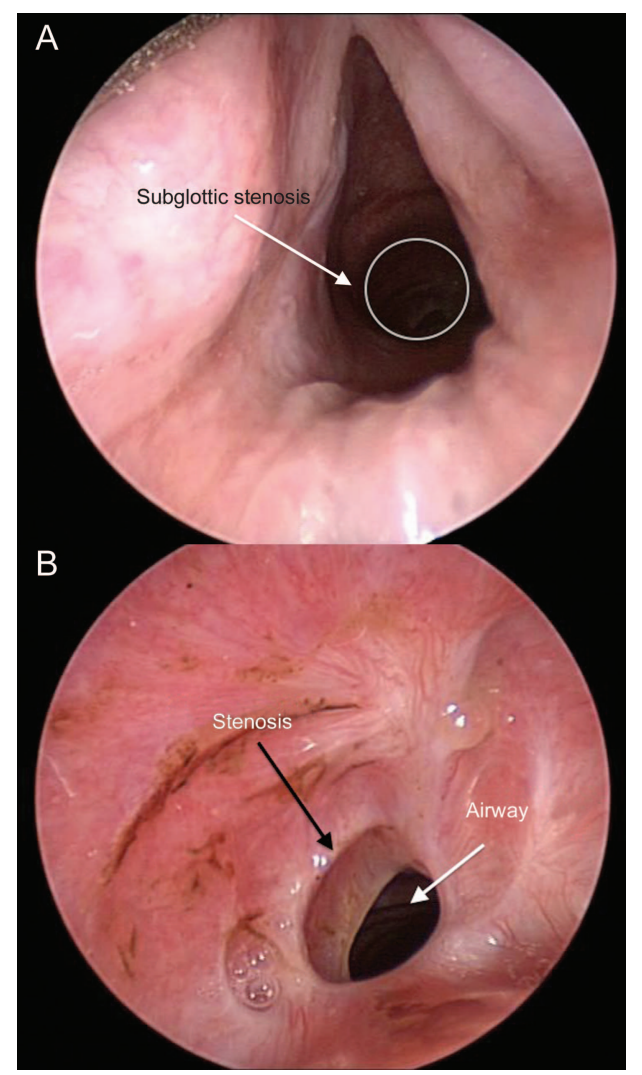

Fig. 5. Postintubation tracheal stenosis. A: Views from above the vocal cords. B: Views from below the vocal cords.

promise the airway and lead to dyspnea, stridor, or respiratory failure. ${ }^{81}$ As the scar matures in the weeks after extubation, the posterior glottis becomes progressively narrower, resulting in the development of exertional dyspnea with inspiratory stridor. If an office laryngeal examination confirms that vocal cord abduction is reduced or absent, further laryngeal examination of the patient under anes- 
thesia may be warranted to examine the posterior glottis. Palpation of the bilateral arytenoids can be used to differentiate posterior glottic scarring from neurogenic paralysis, and endoscopic examination of the subglottis and trachea can help to rule out synchronous lesions. In addition, laryngeal electromyography may aid in differentiating neurogenic and mechanical sources of immobility.

The anesthesiologist and the otolaryngologist should discuss airway management of a patient before beginning operative treatment of laryngotracheal stenosis. Routine intubation of a patient with airway stenosis may or may not be possible, and safe operative intervention requires that contingency plans be discussed in advance. The stenotic site can limit tube passage, causing trauma to the mucosa, promoting edema and swelling of the tissues, and potentially leading to complete airway obstruction. Managing the airway in cases of severe stenosis may require that a tracheotomy be performed with the patient awake and under local anesthesia. After the tracheotomy, ventilation can be provided via the tracheal stoma, and the larynx can be evaluated without the ETT hindering visualization or obstructing the surgical site. However, patients with a stable airway may benefit from less invasive modalities, such as jet ventilation, if the stenosis allows for adequate exhalation without air trapping. Intermittent ventilation through rigid bronchoscopy is also an alternative, although the frequent insertion and removal of the scope throughout the surgical procedure may be cumbersome.

During endoscopic evaluation of posterior glottic stenosis, joint mobility should be assessed by palpation. If the joint is mobile, but scar tissue causes immobility of the posterior commissure, the scar tissue can be divided with posterior glottic lysis to help re-establish mobility. Cold instrumentation or a laser can be used for microsurgical scar excision. However, restenosis can occur if raw surfaces appose during healing. Rotation of mucosal flaps into the exposed surfaces may prevent adhesion formation and restenosis. ${ }^{82,83}$ If the glottic scar does not respond to conservative lysis of the posterior commissure, then unilateral cordotomy and partial arytenoidectomy may help improve glottic airway patency, although at the cost of possible breathy dysphonia.

The management of subglottic and tracheal stenosis depends largely on the characteristics of the stenotic region as seen by endoscopy. It is important to measure the distance from the glottis to the onset of the stenotic segment, the length of the stenosis, and the distance from the distal portion of the stenosis to the tracheal stoma (if the patient has already had a tracheotomy). Treatment includes endoscopic procedures, such as serial dilations with rigid bronchoscopy, balloon dilations, and laser resection. Historical success rates of endoscopic procedures range between 44 and $68 \%{ }^{84-86}$ However, these procedures are usually most effective in the treatment of thin web-like lesions that are no longer than $2 \mathrm{~cm}$. Mitomycin $\mathrm{C}$, an antineoplastic agent that inhibits fibroblast proliferation, has been shown to be an effective adjuvant in preventing restenosis, ${ }^{87}$ although many reports are anecdotal, and the literature lacks controlled studies. In addition, the use of T-tube stenting can be considered if multiple endoscopic treatments have failed to correct the stenosis. External procedures, such as laryngotracheal reconstruction with anterior and/or posterior cartilage grafting and cricotracheal/tracheal resection with anastomosis, are possible options for stenoses longer than $2 \mathrm{~cm}$ or for patients in whom multiple endoscopic procedures have failed.

Structural Changes to the Trachea. The most common causes of acquired tracheomalacia are cuffed endotracheal or tracheotomy tubes. ${ }^{88}$ The pathophysiology of tracheomalacia has been described as a combination of pressure necrosis secondary to elevated cuff pressures, mechanical erosion due to movement of the tube, chronic inflammation, and infection contributing to thinning and destruction of the tracheal cartilages. ${ }^{88,89}$ Loss of this cartilaginous support causes weakening of the tracheal wall, followed by collapse and airway obstruction during respiration. Clinical manifestations can range from mild dyspnea, chronic cough, and wheezing to more serious airway events, such as stridor, airway compromise, and eventual respiratory failure..$^{90}$ Management of tracheomalacia includes tracheotomy to bypass the malacic site, ${ }^{91}$ intraluminal stenting, ${ }^{90}$ external stabilization with stenting, ${ }^{92}$ and surgical resection of the malacic segment with end-to-end anastomosis.

Tracheotomy and prolonged intubation may lead to another rare yet devastating complication: tracheoinnominate artery fistula. The pathophysiologic mechanism involves pressure necrosis of the tube tip or cuff with subsequent erosion of the anterior tracheal wall. ${ }^{93}$ This erosion can cause a fistulous communication between the trachea and the innominate artery as it passes anteriorly across the trachea. The clinical presentation of tracheoinnominate artery fistula is classically described as a sentinel bleed followed by massive hemoptysis. ${ }^{93,94}$ Its diagnosis requires a high index of clinical suspicion because other diagnostic modalities, such as angiography, can delay management and lead to death. An immediate intervention that can be used to stop the bleeding is hyperinflation of the tracheotomy cuff. If this fails to control bleeding, the tracheotomy tube should be replaced by an ETT through the tracheostoma so that the cuff can be inflated distal to the bleeding site; digital pressure with a finger inserted through the stoma into the airway can help compress the anterior tracheal wall and innominate artery against the sternum. This compression may slow acute bleeding in $90 \%$ of patients $^{94}$ and allow time for emergent transport to the operating room, where definitive management can take place. Tracheoinnominate artery fistula is a life-threaten- 
Table 1. Video Laryngoscope Complications: Summary of Case Reports

\begin{tabular}{|c|c|c|c|}
\hline Injury Type & Mechanism & Repair & Reference \\
\hline \multirow[t]{2}{*}{ Palatoglossal arch } & Blind insertion of styleted tube into pharynx & No & Hsu et al ${ }^{100}$ \\
\hline & $\begin{array}{l}\text { Rigid styleted tube, focusing on monitor and not oral } \\
\text { cavity }\end{array}$ & No & Hirabayashi ${ }^{101}$ \\
\hline \multirow[t]{3}{*}{ Palatopharyngeal arch } & $\begin{array}{l}\text { Styleted tube inserted laterally and blindly rotated } \\
\text { anteriorly to bring into view }\end{array}$ & No & Leong et $\mathrm{al}^{102}$ \\
\hline & $\mathrm{NR}$ & Yes, suture & Cooper ${ }^{103}$ \\
\hline & NR & Yes, cautery & Cooper ${ }^{103}$ \\
\hline \multirow[t]{6}{*}{ Soft palate } & $\begin{array}{l}\text { Rigid styleted tube, focusing on monitor and not on oral } \\
\text { cavity }\end{array}$ & No & Vincent et al ${ }^{104}$ \\
\hline & $\begin{array}{l}\text { Styleted tube inserted laterally and blindly rotated } \\
\text { anteriorly to bring into view }\end{array}$ & No & Cross et al ${ }^{108}$ \\
\hline & $\begin{array}{l}\text { McGrath video laryngoscope, styleted tube, blind spot } \\
\text { while focusing on monitor and not oral cavity }\end{array}$ & Yes, suture & Williams and Ball ${ }^{105}$ \\
\hline & $\begin{array}{l}\text { Rigid styleted tube, focusing on monitor and not on oral } \\
\text { cavity }\end{array}$ & No & Hsu et al ${ }^{106}$ \\
\hline & $\begin{array}{l}\text { Rigid styleted tube, focusing on monitor and not on oral } \\
\text { cavity }\end{array}$ & Yes, suture & Chin et al ${ }^{107}$ \\
\hline & $\begin{array}{l}\text { Rigid styleted tube, focusing on monitor and not on oral } \\
\text { cavity; tube inserted laterally and blindly rotated } \\
\text { anteriorly to bring into view }\end{array}$ & No & Cross et al ${ }^{108}$ \\
\hline Tonsillar pillar & $\begin{array}{l}\text { Blind intubation while focusing on monitor; standard } \\
\text { tube, not rigid stylet as recommended by manufacturer }\end{array}$ & No & Malik and Frogel109 \\
\hline $\begin{array}{l}\text { Retromolar trigone, possible lingual } \\
\text { nerve injury }\end{array}$ & Blind tube placement using rigid stylet & No & Magboul and Joel ${ }^{110}$ \\
\hline Base of tongue & NR & Unknown & Dupanovic $^{111}$ \\
\hline $\begin{array}{l}\text { Dental }(n=2) \text {, vocal cord }(n=1), \\
\quad \text { trachea }(n=1), \text { hypopharynx }(n=1), \\
\text { tonsil }(n=1)\end{array}$ & NR & Unknown & Aziz et al ${ }^{112}$ \\
\hline NR $=$ not reported & & & \\
\hline
\end{tabular}

ing complication with a published survival rate of only $14 \%$; the key to potential survival is immediate surgery. ${ }^{95}$

A tracheoesophageal fistula may also develop as a result of prolonged endotracheal intubation or tracheotomy. The mechanism of injury is similar to that of tracheomalacia and tracheoinnominate fistula, in which elevated cuff pressures, necrosis of the mucosa, and subsequent erosion of the tracheoesophageal wall can lead to a fistulous tract between the posterior wall of the trachea and the anterior wall of the esophagus. This complication is more commonly identified in the ICU setting when patients are still critically ill and dependent upon prolonged mechanical ventilation. Risk factors include diabetes, infection, and the presence of a nasogastric tube. ${ }^{96,97}$ Clinically, a tracheoesophageal fistula can be identified when food content is suctioned from the ETT or if the patient presents with coughing during feeding, recurrent aspiration pneumonia, positive cuff leak, or gastric distention. ${ }^{98}$ Diagnosis can be confirmed with radiology studies, such as an esophagram or computed tomography scan, or instead confirmed with esophagoscopy and bronchoscopy. Once the diagno- sis is established, surgical repair is required because spontaneous closure is rare. ${ }^{97,99}$

\section{Special Considerations}

Video Laryngoscopy Injuries. Since the introduction of the video laryngoscope in 2002, a series of case reports have been published that document the complications encountered with its use (Table 1). ${ }^{100-112}$ The most common complication is injury to the soft palate, although injuries to the teeth, larynx, tongue, and retromolar trigone have also been described. ${ }^{110-112}$ The oropharynx is specifically at risk of injury because the video laryngoscope causes the tonsillar pillars to elevate and stretch anteriorly, making them more prone to injury as the tube is being advanced. ${ }^{102}$ The mechanism of injury with the video laryngoscope differs from that with traditional intubation. The soft tissue damage in traditional laryngoscopy is caused mainly by insertion of the laryngoscope, but soft tissue injury with the video laryngoscope is caused by insertion of the ETT itself, as it is often maneuvered blindly into and through 
the oral cavity and pharynx until it is finally in view at the video laryngoscope monitor. Injuries often occur because of the natural tendency of the intubator to focus on the monitor and not toward the oral cavity or oropharynx during tube insertion. ${ }^{103,105}$ In addition, Dupanovic ${ }^{111}$ described the GlideScope GVL's (LoPro medical blade, Verathon, Bothell, Washington) 2 blind spots: one at its inferior aspect and the other at its lateral aspect. These preclude direct visualization of the ETT as it is being inserted by the operator.

The proprietary stylet marketed with the GlideScope is designed to follow the curve of the video laryngoscope. This stylet is more rigid than a standard ETT stylet and may increase the risk of soft tissue injury. Studies have demonstrated that a standard ETT stylet is equally successful for intubation when used by novice and experienced operators. ${ }^{113,114}$

Management depends on the severity of soft tissue injury; mild lacerations can be managed conservatively, whereas more substantial injuries may benefit from hemostasis and primary repair. In a literature review by Leong et al, ${ }^{102}$ all 11 patients suffered injury to the soft palate, mainly the palatopharyngeal arch, the palatoglossal arch, and the anterior tonsillar pillar. However, only 4 of 11 patients required otolaryngology intervention. Two patients required sutures, and 2 patients required electrocautery to control bleeding. ${ }^{103,107}$

To reduce the incidence of this complication, several authors have proposed different techniques of tube insertion: (1) always maintain the tip of the tube close and parallel to the blade until it is viewed in the monitor, (2) keep the tube in direct vision during placement and refrain from looking back to the monitor until the tip has passed out of direct vision, and (3) insert the tube in the midline with the proximal portion oriented to the right and then rotate counterclockwise $90^{\circ}$ to bring the tip into view. ${ }^{102,103,111}$ Knowledge of these complications and the techniques to prevent them is paramount in reducing patient morbidity.

Several other video laryngoscopes have been introduced to the market recently. Though reports of injury with use of these other videoscopes are rare, it should be assumed that the risk of injury is equivalent to that of the GlideScope, and similar precautions should be taken to prevent injury.

Supraglottic Airway Device Injuries. Introduced in 1991, the laryngeal mask airway (LMA) was the first supraglottic airway device created for use as an alternative to endotracheal intubation. Several supraglottic airway devices are now available and are currently used in many settings. These devices can be used in the emergent setting when endotracheal intubation is unsuccessful and in the controlled operating room setting as a less invasive alter- native to endotracheal intubation. Risks and complications have only recently been reported for the LMA, even though it is generally considered to be safer than endotracheal intubation.

Reported soft tissue injuries from the LMA include tongue ischemia, ${ }^{115}$ as well as both unilateral and bilateral recurrent laryngeal, ${ }^{16,117}$ hypoglossal, ${ }^{118}$ and lingual ${ }^{119}$ nerve injuries. The proposed injurious mechanism is similar to that described with classic ETT injury: direct mechanical compression of the nerve between the LMA cuff and the cricoid as it ascends at the apex of the pyriform fossa. ${ }^{116}$ The increase in cuff pressure is not necessarily caused by manual overinflation. Instead, it has been postulated that nitrous oxide from gas anesthesia diffuses into the supraglottic airway device cuff and inadvertently increases cuff pressure. ${ }^{117}$ As this cuff pressure exceeds capillary perfusion pressure, the nerve may undergo neuropraxic injury and manifest clinically as vocal cord paralysis, hemi-tongue paralysis, tongue anesthesia, etc. ${ }^{120}$

Most of these injuries are transient and will likely resolve spontaneously. In a literature review, Endo et al ${ }^{117}$ reported that only 2 of 14 patients had permanent injuries after LMA use. To prevent neural damage, El Toukhy and Tweedie ${ }^{119}$ listed a series of points: (1) select the appropriate size for supraglottic airway devices; (2) avoid cuff pressures that exceed $60 \mathrm{~cm} \mathrm{H}_{2} \mathrm{O}$; (3) when using nitrous oxide, routinely measure cuff pressure every $30 \mathrm{~min}$; (4) avoid extreme neck positions; and (5) have a low threshold of suspicion for nerve damage.

\section{Conclusion}

Endotracheal intubation can be a safe, life-saving procedure. Although rare, acute or chronic injuries can occur during endotracheal intubation. Emergent and difficult intubations are significant risk factors for airway injury. The skill level of the provider performing the intubation has also been studied, but results in the literature have been conflicting. Likewise, the role of patient factors, such as age, gender, and obesity, and how they relate to complications are still controversial. Soft tissue hematomas and lacerations may occur in the nasal and oral cavities, oropharynx, and larynx. These injuries are caused mostly by mishaps during laryngoscopy or tube insertion. Most of these injuries heal on their own without causing severe symptoms or permanent sequelae.

More serious injuries should be considered when symptoms such as hoarseness, dysphagia, and breathing difficulties ensue or persist. In these cases, vocal cord paralysis, arytenoid dislocation, and laryngotracheal stenosis must be considered as possible etiologies. Such airway injuries may develop after prolonged intubation when laryngotracheal tissues are chronically exposed to pressure by the ETT or cuff. This pressure may compress the recurrent 


\section{Complications of Airway Management}

laryngeal nerves and cause temporary or permanent vocal cord paralysis. Likewise, when this pressure exceeds capillary pressure, necrosis, ulceration, and scarring may develop in the subglottis and trachea, leading to the formation of stenosis. Comorbidities and reflux also appear to play a role in the pathogenesis of laryngotracheal stenosis.

Airway management with video laryngoscopes such as the GlideScope may provide better visualization during difficult intubation. However, several recent reports have documented oropharyngeal injury during tube insertion. The most accepted mechanism of injury is blind insertion of the tube by providers who are looking at the GlideScope monitor until the ETT finally comes into view.

The supraglottic airway device is considered a less invasive alternative to endotracheal intubation, but its use also has been associated with soft tissue oral cavity injuries and neuropraxic injury of the recurrent laryngeal, lingual, and hypoglossal nerves. These injuries are believed to be secondary to elevated cuff pressures against the soft tissues of the oral cavity, oropharynx, and hypopharynx.

As the situations leading to airway injury during endotracheal intubation are understood, several key points might aid in the prevention of complications:

- Whenever possible, recruit a second provider to assist during difficult or emergent intubations.

- Seek early otolaryngology evaluation for patients with severe acute soft tissue injuries, for those with severe symptoms after extubation, and for those whose symptoms (hoarseness, dysphagia, aspiration) persist beyond 1 month after extubation.

- Consider patients with comorbid conditions at higher risk of long-term airway complications and manage accordingly.

- Monitor cuff pressures and, whenever possible, limit prolonged intubation, as these may lead to vocal cord paralysis or laryngotracheal stenosis.

- For video laryngoscope intubations, directly visualize the ETT within the oral cavity until the tip of the ETT can be viewed on the video monitor.

- Choose a supraglottic airway device that is adequately sized for the patient and monitor cuff pressures.

\section{REFERENCES}

1. Martin LD, Mhyre JM, Shanks AM, Tremper KK, Kheterpal S. 3,423 Emergency tracheal intubations at a university hospital: airway outcomes and complications. Anesthesiology 2011;114(1):4248

2. Domino KB, Posner KL, Caplan RA, Cheney FW. Airway injury during anesthesia: a closed claims analysis. Anesthesiology 1999; 91(6):1703-1711.
3. Cook TM, Scott S, Mihai R. Litigation related to airway and respiratory complications of anaesthesia: an analysis of claims against the NHS in England 1995-2007. Anaesthesia 2010;65(6):556-563.

4. Bhatti NI, Mohyuddin A, Reaven N, Funk SE, Laeeq K, Pandian V, et al. Cost analysis of intubation-related tracheal injury using a national database. Otolaryngol Head Neck Surg 2010;143(1):31-36.

5. Shiga T, Wajima Z, Inoue $T$, Sakamoto A. Predicting difficult intubation in apparently normal patients: a meta-analysis of bedside screening test performance. Anesthesiology 2005;103(2):429-437.

6. Mort TC. Emergency tracheal intubation: complications associated with repeated laryngoscopic attempts. Anesth Analg 2004;99(2): 607-613.

7. Benedetto WJ, Hess DR, Gettings E, Bigatello LM, Toon H, Hurford WE, Schmidt U. Urgent tracheal intubation in general hospital units: an observational study. J Clin Anesth 2007;19(1):20-24.

8. Schmidt UH, Kumwilaisak K, Bittner E, George E, Hess D. Effects of supervision by attending anesthesiologists on complications of emergency tracheal intubation. Anesthesiology 2008;109(6):973977.

9. Mhyre JM, Martin LD, Ramachandran SK, Kheterpal S. Is faculty presence during emergent tracheal intubations justified? Anesthesiology 2009;111(1):217-218; author reply 218-219.

10. Jaber S, Amraoui J, Lefrant JY, Arich C, Cohendy R, Landreau L, et al. Clinical practice and risk factors for immediate complications of endotracheal intubation in the intensive care unit: a prospective, multiple-center study. Crit Care Med 2006;34(9):2355-2361.

11. Kikura M, Suzuki K, Itagaki T, Takada T, Sato S. Age and comorbidity as risk factors for vocal cord paralysis associated with tracheal intubation. Br J Anaesth 2007;98(4):524-530.

12. Benjamin B, Holinger LD. Laryngeal complications of endotracheal intubation. Ann Otol Rhinol Laryngol 2008;117:1-20.

13. Mort TC. Complications of emergency tracheal intubation: immediate airway-related consequences: part II. J Intensive Care Med 2007;22(4):208-215.

14. Walner DL, Stern Y, Gerber ME, Rudolph C, Baldwin CY, Cotton RT. Gastroesophageal reflux in patients with subglottic stenosis. Arch Otolaryngol Head Neck Surg 1998;124(5):551-555.

15. Darmon JY, Rauss A, Dreyfuss D, Bleichner G, Elkharrat D, Schlemmer B, et al. Evaluation of risk factors for laryngeal edema after tracheal extubation in adults and its prevention by dexamethasone. A placebo-controlled, double-blind, multicenter study. Anesthesiology 1992;77(2):245-251.

16. Tadié JM, Behm E, Lecuyer L, Benhmamed R, Hans S, Brasnu D, et al. Post-intubation laryngeal injuries and extubation failure: a fiberoptic endoscopic study. Intensive Care Med 2010;36(6):991998.

17. Poetker DM, Ettema SL, Blumin JH, Toohill RJ, Merati AL. Association of airway abnormalities and risk factors in 37 subglottic stenosis patients. Otolaryngol Head Neck Surg 2006;135(3):434437.

18. Divatia J, Bhowmick K. Complications of endotracheal intubation and other airway management procedures. Indian J Anaesth 2005; 49(4):308-318.

19. Bishop MJ, Weymuller EA Jr, Fink BR. Laryngeal effects of prolonged intubation. Anesth Analg 1984;63(3):335-342.

20. Colton House J, Noordzij JP, Murgia B, Langmore S. Laryngeal injury from prolonged intubation: a prospective analysis of contributing factors. Laryngoscope 2011;121(3):596-600.

21. Holmberg TJ, Bowman SM, Warner KJ, Vavilala MS, Bulger EM, Copass MK, Sharar SR. The association between obesity and difficult prehospital tracheal intubation. Anesth Analg 2011;112(5): 1132-1138. 


\section{Complications of Airway Management}

22. Hekiert AM, Mandel J, Mirza N. Laryngoscopies in the obese: predicting problems and optimizing visualization. Ann Otol Rhinol Laryngol 2007;116(4):312-316.

23. Juvin P, Lavaut E, Dupont H, Lefevre P, Demetriou M, Dumoulin JL, Desmonts JM. Difficult tracheal intubation is more common in obese than in lean patients. Anesth Analg 2003;97(2):595-600.

24. Kabon B, Nagele A, Reddy D, Eagon C, Fleshman JW, Sessler DI, Kurz A. Obesity decreases perioperative tissue oxygenation. Anesthesiology 2004;100(2):274-280.

25. Dargin JM, Emlet LL, Guyette FX. The effect of body mass index on intubation success rates and complications during emergency airway management. Intern Emerg Med 2013;8(1):75-82

26. Sim WS, Chung IS, Chin JU, Park YS, Cha KJ, Lee SC, Kim YC. Risk factors for epistaxis during nasotracheal intubation. Anaesth Intensive Care 2002;30(4):449-452.

27. O'Connell JE, Stevenson DS, Stokes MA. Pathological changes associated with short-term nasal intubation. Anaesthesia 1996;51(4): 347-350.

28. Watanabe S, Yaguchi Y, Suga A, Asakura N. A "bubble-tip" (Airguide) tracheal tube system: its effects on incidence of epistaxis and ease of tube advancement in the subglottic region during nasotracheal intubation. Anesth Analg 1994;78(6):1140-1143.

29. Chen YH, Chen JY, Hsu CS, Huang CT, So E. Recurrent epistaxis following nasotracheal intubation: a case report. Acta Anaesthesiol Sin 1996;34(2):93-96.

30. Coe TR, Human M. The peri-operative complications of nasal intubation: a comparison of nostril side. Anaesthesia 2001;56(5):447450.

31. Sanuki T, Hirokane M, Kotani J. Epistaxis during nasotracheal intubation: a comparison of nostril sides. J Oral Maxillofac Surg 2010;68(3):618-621.

32. Tong JL, Malanjum LS. Reducing epistaxis during nasotracheal intubation. Anesth Analg 2008;106(6):1923-1924; author reply 1924.

33. Cavusoglu T, Yazici I, Demirtas Y, Gunaydin B, Yavuzer R. A rare complication of nasotracheal intubation: accidental middle turbinectomy. J Craniofac Surg 2009;20(2):566-568.

34. Dost P, Armbruster W. Nasal turbinate dislocation caused by nasotracheal intubation. Acta Anaesthesiol Scand 1997;41(6):795-796.

35. Scott AR, Gray ST. Oropharyngeal foreign body after attempted nasal intubation: a case of traumatic middle turbinectomy. Laryngoscope 2007;117(6):1094-1095.

36. Bozdogan N, Sener M, Yavuz H, Yilmazer C, Turkoz A, Arslan G. Retropharyngeal submucosal dissection due to nasotracheal intubation. B-ENT 2008;4(3):179-81.

37. Krebs MJ, Sakai T. Retropharyngeal dissection during nasotracheal intubation: a rare complication and its management. J Clin Anesth 2008;20(3):218-221.

38. Salord F, Gaussorgues P, Marti-Flich J, Sirodot M, Allimant C, Lyonnet D, Robert D. Nosocomial maxillary sinusitis during mechanical ventilation: a prospective comparison of orotracheal versus the nasotracheal route for intubation. Intensive Care Med 1990; 16(6):390-393

39. Holzapfel L, Chevret S, Madinier G, Ohen F, Demingeon G, Coupry A, Chaudet M. Influence of long-term oro- or nasotracheal intubation on nosocomial maxillary sinusitis and pneumonia: results of a prospective, randomized, clinical trial. Crit Care Med 1993;21(8):1132-1138.

40. Katz RI, Hovagim AR, Finkelstein HS, Grinberg Y, Boccio RV, Poppers PJ. A comparison of cocaine, lidocaine with epinephrine, and oxymetazoline for prevention of epistaxis on nasotracheal intubation. J Clin Anesth 1990;2(1):16-20.

41. Kim YC, Lee SH, Noh GJ, Cho SY, Yeom JH, Shin WJ, et al. Thermosoftening treatment of the nasotracheal tube before intuba- tion can reduce epistaxis and nasal damage. Anesth Analg 2000; 91(3):698-701.

42. Alvarez H, Osorio J, De Diego JI, Prim MP, De La Torre C, Gavilan J. Sequelae after nasal septum injuries in children. Auris Nasus Larynx 2000;27(4):339-342.

43. Cain J, Roy S. Nasal septal abscess. Ear Nose Throat J 2011;90(4): 144-147.

44. Owen H, Waddell-Smith I. Dental trauma associated with anaesthesia. Anaesth Intensive Care 2000;28(2):133-145

45. Warner ME, Benenfeld SM, Warner MA, Schroeder DR, Maxson PM. Perianesthetic dental injuries: frequency, outcomes, and risk factors. Anesthesiology 1999;90(5):1302-1305.

46. Wu K, Ahmed A. Penetrating injury to the soft palate causing retropharyngeal air collection. Emerg Med J 2005;22(2):148-149.

47. Borges G, Bonilha L, Santos SF, Carelli EF, Fernandes YB, Ramina $\mathrm{R}$, et al. Thrombosis of the internal carotid artery secondary to soft palate injury in children and childhood. Report of two cases. Pediatr Neurosurg 2000;32(3):150-153.

48. Santos PM, Afrassiabi A, Weymuller EA Jr. Risk factors associated with prolonged intubation and laryngeal injury. Otolaryngol Head Neck Surg 1994;111(4):453-459.

49. Mendels EJ, Brunings JW, Hamaekers AE, Stokroos RJ, Kremer B, Baijens LW. Adverse laryngeal effects following short-term general anesthesia: a systematic review. Arch Otolaryngol Head Neck Surg 2012;138(3):257-264.

50. Hamdan AL, Sibai A, Rameh C, Kanazeh G. Short-term effects of endotracheal intubation on voice. J Voice 2007;21(6):762-768.

51. Kitahara S, Masuda Y, Kitagawa Y. Vocal fold injury following endotracheal intubation. J Laryngol Otol 2005;119(10):825-827.

52. Yamanaka H, Hayashi Y, Watanabe Y, Uematu H, Mashimo T. Prolonged hoarseness and arytenoid cartilage dislocation after tracheal intubation. Br J Anaesth 2009;103(3):452-455.

53. Sariego J. Vocal fold hypomobility secondary to elective endotracheal intubation: a general surgeon's perspective. J Voice 2010; 24(1):110-112.

54. Rosenthal LH, Benninger MS, Deeb RH. Vocal fold immobility: a longitudinal analysis of etiology over 20 years. Laryngoscope 2007; 117(10):1864-1870

55. Benninger MS, Gillen JB, Altman JS. Changing etiology of vocal fold immobility. Laryngoscope 1998;108(9):1346-1350.

56. Cavo JW Jr. True vocal cord paralysis following intubation. Laryngoscope 1985;95(11):1352-1359.

57. Myssiorek D. Recurrent laryngeal nerve paralysis: anatomy and etiology. Otolaryngol Clin North Am 2004;37(1):25-44.

58. Garg R, Rath GP, Bithal PK, Prabhakar H, Marda MK. Effects of retractor application on cuff pressure and vocal cord function in patients undergoing anterior cervical discectomy and fusion. Indian J Anaesth 2010;54(4):292-295.

59. Kriskovich MD, Apfelbaum RI, Haller JR. Vocal fold paralysis after anterior cervical spine surgery: incidence, mechanism, and prevention of injury. Laryngoscope 2000;110(9):1467-1473.

60. Audu P, Artz G, Scheid S, Harrop J, Albert T, Vaccaro A, et al. Recurrent laryngeal nerve palsy after anterior cervical spine surgery: the impact of endotracheal tube cuff deflation, reinflation, and pressure adjustment. Anesthesiology 2006;105(5):898-901.

61. Weisberg NK, Spengler DM, Netterville JL. Stretch-induced nerve injury as a cause of paralysis secondary to the anterior cervical approach. Otolaryngol Head Neck Surg 1997;116(3):317-326.

62. Xu W, Han D, Hu R, Bai Y, Zhang L. Characteristics of vocal fold immobility following endotracheal intubation. Ann Otol Rhinol Laryngol 2012;121(10):689-694.

63. Koufman JA, Walker FO, Joharji GM. The cricothyroid muscle does not influence vocal fold position in laryngeal paralysis. Laryngoscope 1995;105(4 Pt 1):368-372. 


\section{Complications of Airway Management}

64. Woodson GE. Configuration of the glottis in laryngeal paralysis. I: Clinical study. Laryngoscope 1993;103(11 Pt 1):1227-1234.

65. Rosen CA, Simpson CB. Principles of vocal fold augmentation. In: Operative techniques in laryngology. Berlin: Springer-Verlag; 2008: 29-35.

66. Harries ML, Morrison M. The role of stroboscopy in the management of a patient with a unilateral vocal fold paralysis. J Laryngol Otol 1996;110(2):141-143.

67. Young VN, Smith LJ, Rosen C. Voice outcome following acute unilateral vocal fold paralysis. Ann Otol Rhinol Laryngol 2013; 122(3):197-204.

68. Kasperbauer JL. A biomechanical study of the human cricoarytenoid joint. Laryngoscope 1998;108(11 Pt 1):1704-1711.

69. Friedman AD, Kobler JB, Landau-Zemer T, Barbu AM, Burns JA. High-force simulated intubation fails to dislocate cricoarytenoid joint in ex vivo human larynges. Ann Otol Rhinol Laryngol 2012; 121(11):746-753.

70. Paulsen FP, Jungmann K, Tillmann BN. The cricoarytenoid joint capsule and its relevance to endotracheal intubation. Anesth Analg 2000;90(1):180-185.

71. Rubin AD, Hawkshaw MJ, Moyer CA, Dean CM, Sataloff RT. Arytenoid cartilage dislocation: a 20-year experience. J Voice 2005; 19(4):687-701.

72. Close LG, Merkel M, Watson B, Schaefer SD. Cricoarytenoid subluxation, computed tomography, and electromyography findings. Head Neck Surg 1987;9(6):341-348.

73. Paulsen FP, Rudert HH, Tillmann BN. New insights into the pathomechanism of postintubation arytenoid subluxation. Anesthesiology 1999;91(3):659-666.

74. Sataloff RT. Arytenoid dislocation: techniques of surgical reduction. Operative Tech Otolaryngol Head Neck Surg 1998;9(4):196202.

75. Peña J, Cicero R, Marín J, Ramírez M, Cruz S, Navarro F. Laryngotracheal reconstruction in subglottic stenosis: an ancient problem still present. Otolaryngol Head Neck Surg 2001;125(4):397-400.

76. Koshkareva Y, Gaughan JP, Soliman AM. Risk factors for adult laryngotracheal stenosis: a review of 74 cases. Ann Otol Rhinol Laryngol 2007;116(3):206-210.

77. Whited RE. A prospective study of laryngotracheal sequelae in long-term intubation. Laryngoscope 1984;94(3):367-377.

78. Gaynor EB, Greenberg SB. Untoward sequelae of prolonged intubation. Laryngoscope 1985;95:1461-1467.

79. Gaynor EB. Gastroesophageal reflux as an etiologic factor in laryngeal complications of intubation. Laryngoscope 1988;98(9):972979.

80. Anand VK, Alemar G, Warren ET. Surgical considerations in tracheal stenosis. Laryngoscope 1992;102(3):237-243.

81. Carrat X, Verhulst J, Duroux S, Pescio P, Devars F, Traissac L. Postintubation interarytenoid adhesion. Ann Otol Rhinol Laryngol 2000;109(8 Pt 1):736-740.

82. Dedo HH, Sooy CD. Endoscopic laser repair of posterior glottic, subglottic and tracheal stenosis by division or micro-trapdoor flap. Laryngoscope 1984;94(4):445-450.

83. Chitose S, Umeno H, Nakashima T. Endoscopic surgical treatment of posterior glottic stenosis. J Laryngol Otol Suppl 2009;(31):68-71.

84. Simpson GT, Strong MS, Healy GB, Shapshay SM, Vaughan CW. Predictive factors of success or failure in the endoscopic management of laryngeal and tracheal stenosis. Ann Otol Rhinol Laryngol 1982;91(4 Pt 1):384-388.

85. Carruth JA. The role of lasers in otolaryngology. World J Surg 1983;7(6):719-724.

86. Ossoff RH, Tucker GF Jr, Duncavage JA, Toohill RJ. Efficacy of bronchoscopic carbon dioxide laser surgery for benign strictures of the trachea. Laryngoscope 1985;95(10):1220-1223.
87. Rahbar R, Shapshay SM, Healy GB. Mitomycin: effects on laryngeal and tracheal stenosis, benefits, and complications. Ann Otol Rhinol Laryngol 2001;110(1):1-6.

88. Feist JH, Johnson TH, Wilson RJ. Acquired tracheomalacia: etiology and differential diagnosis. Chest 1975;68(3):340-345.

89. Ferguson GT, Benoist J. Nasal continuous positive airway pressure in the treatment of tracheobronchomalacia. Am Rev Respir Dis 1993;147(2):457-461.

90. Ernst A, Majid A, Feller-Kopman D, Guerrero J, Boiselle P, Loring $\mathrm{SH}$, et al. Airway stabilization with silicone stents for treating adult tracheobronchomalacia: a prospective observational study. Chest 2007;132(2):609-616.

91. Kandaswamy C, Balasubramanian V. Review of adult tracheomalacia and its relationship to chronic obstructive pulmonary disease. Curr Opin Pulm Med 2009;15(2):113-119.

92. Cho JH, Kim H, Kim J. External tracheal stabilization technique for acquired tracheomalacia using a tailored silicone tube. Ann Thorac Surg 2012;94(4):1356-1358.

93. Kapural L, Sprung J, Gluncic I, Kapural M, Andelinovic S, Primorac D, Schoenwald PK. Tracheo-innominate artery fistula after tracheostomy. Anesth Analg 1999;88(4):777-780.

94. Jones JW, Reynolds M, Hewitt RL, Drapanas T. Tracheo-innominate artery erosion: successful surgical management of a devastating complication. Ann Surg 1976;184(2):194-204.

95. Wood DE, Mathisen DJ. Late complications of tracheotomy. Clin Chest Med 1991;12(3):597-609.

96. Montgomery WW. Surgery of the trachea. In: Surgery of the upper respiratory system, volume II. Philadelphia: Lea \& Febiger; 1989; 365-443.

97. Dartevelle P, Macchiarini P. Management of acquired tracheoesophageal fistula. Chest Surg Clin N Am 1996;6(4):819-836.

98. Mooty RC, Rath P, Self M, Dunn E, Mangram A. Review of tracheoesophageal fistula associated with endotracheal intubation. J Surg Educ 2007;64(4):237-240.

99. Reed MF, Mathisen DJ. Tracheoesophageal fistula. Chest Surg Clin N Am 2003;13(2):271-289.

100. Hsu WT, Tsao SL, Chen KY, Chou WK. Penetrating injury of the palatoglossal arch associated with use of the GlideScope videolaryngoscope in a flame burn patient. Acta Anaesthesiol Taiwan 2008; 46(1):39-41.

101. Hirabayashi Y. Pharyngeal injury related to GlideScope videolaryngoscope (letter). Otolaryngol Head Neck Surg 2007;137(1):175176.

102. Leong WL, Lim Y, Sia AT. Palatopharyngeal wall perforation during Glidescope intubation. Anaesth Intensive Care 2008;36(6):870874.

103. Cooper RM. Complications associated with the use of the GlideScope videolaryngoscope. Can J Anaesth 2007;54(1):54-57.

104. Vincent RD Jr, Wimberly MP, Brockwell RC, Magnuson JS. Soft palate perforation during orotracheal intubation facilitated by the GlideScope videolaryngoscope. J Clin Anesth 2007;19(8):619-621.

105. Williams D, Ball DR. Palatal perforation associated with McGrath videolaryngoscope. Anaesthesia 2009;64(10):1144-1145.

106. Hsu WT, Hsu SC, Lee YL, Huang JS, Chen CL. Penetrating injury of the soft palate during GlideScope intubation. Anesth Analg 2007; 104(6):1609-1610; discussion 1611.

107. Chin KJ, Arango MF, Paez AF, Turkstra TP. Palatal injury associated with the GlideScope. Anaesth Intensive Care 2007;35(3): 449-450.

108. Cross P, Cytryn J, Cheng KK. Perforation of the soft palate using the GlideScope videolaryngoscope. Can J Anaesth 2007;54(7):588-589.

109. Malik AM, Frogel JK. Anterior tonsillar pillar perforation during GlideScope video laryngoscopy. Anesth Analg 2007;104(6):16101611; discussion 1611. 


\section{Complications of Airway Management}

110. Magboul MM, Joel S. The video laryngoscopes blind spots and possible lingual nerve injury by the Gliderite rigid stylet-case presentation and review of literature. Middle East J Anesthesiol 2010; 20(6):857-860.

111. Dupanovic M. Maneuvers to prevent oropharyngeal injury during orotracheal intubation with the GlideScope video laryngoscope. J Clin Anesth 2010;22(2):152-154.

112. Aziz MF, Healy D, Kheterpal S, Fu RF, Dillman D, Brambrink AM. Routine clinical practice effectiveness of the Glidescope in difficult airway management: an analysis of 2,004 Glidescope intubations, complications, and failures from two institutions. Anesthesiology 2011;114(1):34-41.

113. Turkstra TP, Harle CC, Armstrong KP, Armstrong PM, Cherry RA, Hoogstra J, Jones PM. The GlideScope-specific rigid stylet and standard malleable stylet are equally effective for GlideScope use. Can J Anaesth 2007;54(11):891-896.

114. Jones PM, Loh FL, Youssef HN, Turkstra TP. A randomized comparison of the GlideRite rigid stylet to a malleable stylet for orotracheal intubation by novices using the GlideScope. Can J Anaesth 2011;58(3):256-261.

115. Gerstein NS, Braude D, Harding JS, Douglas A. Lingual ischemia from prolonged insertion of a Fastrach laryngeal mask airway. West J Emerg Med 2011;12(1):124-127.

116. Zhang J, Zhao Z, Chen Y, Zhang X. New insights into the mechanism of injury to the recurrent laryngeal nerve associated with the laryngeal mask airway. Med Sci Monit 2010;16(5):HY7-HY9.

117. Endo K, Okabe Y, Maruyama Y, Tsukatani T, Furukawa M. Bilateral vocal cord paralysis caused by laryngeal mask airway. Am J Otolaryngol, 2007;28(2):126-129.

118. Nagai K, Sakuramoto C, Goto F. Unilateral hypoglossal nerve paralysis following the use of the laryngeal mask airway. Anaesthesia 1994;49(7):603-604.

119. El Toukhy M, Tweedie O. Bilateral lingual nerve injury associated with classic laryngeal mask airway: a case report. Eur J Anaesthesiol 2012;29(8):400-401.

120. Marjot R. Pressure exerted by the laryngeal mask cuff upon the pharyngeal mucosa. Br J Anesth 1993;70:25-29.

\section{Discussion}

Durbin: We've just gotten in the routine of measuring cuff pressures in ETTs [endotracheal tubes] in the OR [operating room]. One of our residents did a study and found that the pressures were all over the place. We've really focused, and we have cuff pressure manometers on all the anesthesia machines. Our electronic record also supports this, and we have to check off that we did measure cuff pressure and how we did it. There's also a place to record cuff pressure if you placed an LMA [laryngeal mask airway]. I remember the days when we had highpressure low-volume ETT cuffs (red rubber tubes), and the pressure in the cuff had nothing to do with the lateral wall pressure in the trachea. Now, we're saying the pressure in the LMA cuff has something to do with the pressure in the pharyngeal soft tissue structure? I find that hard to understand and even harder to defend. With the high-pressure cuff of the LMA, the pressure really is intercuff pressure, not transmural or across the tissues outside of the cuff. We had to put sensors in the trachea to actually demon- strate that cuff pressure and mucosal pressure were not the same with highpressure low-volume ETT cuffs. Would you comment on that regarding the LMA cuff pressure?

Berkow: The problem is that what we really think matters is tissue perfusion, and we don't know. Some patients may be at higher risk of developing injury because they have poor tissue perfusion. But measuring a cuff pressure tells you what that pressure is, but it doesn't tell you what's happening to the tissue. Since we don't know what the threshold is above which that tissue won't get perfused, that's really still the unanswered question. There have been cases of patients who were young and healthy, everything done right, and they still developed an injury. And then other patients who are extremely high risk and were intubated for many days do fine. So, the problem is that we don't know how to measure the tissue pressures that are really important.

Durbin: It may be the device itself and the pressure contact places on the back or side of it causing injury. Cer- tainly with older ETTs, the placeswhere they rubbed and pressed on the larynx was more important than the cuff pressures were for these longterm injuries or even for short-term injuries. I think we've got a long way to go before we can say a cuff pressure of 40 or 60 in an LMA is a problem. It may be; I don't know. If I can get a seal with less, that seems okay to me. If I need a seal, I think allowing a higher pressure is probably better than giving less and risking aspiration or ventilation failure.

Berkow: The other issue is that the nerves that innervate the larynx and pharynx have a huge amount of variability as far as where they sit, so you never know whether you're potentially stretching or compressing a nerve with your tube or LMA because you don't know for sure where it actually sits. There's so much variation, so that's still an unknown as well.

Blank: I appreciated your thoughts on the safe use of video laryngoscopes, particularly with regard to tube insertion, but I wonder if you have any thoughts about the role of different 
stylets? The proprietary stylet for the GlideScope, for example, is quite rigid. Would a less stiff, malleable stylet be safer?

Berkow: Yes, I didn't include that in my talk, but because of the more acute angle at which you have to insert ETTs with the video laryngoscopes, it's recommended that you use these rigid stylets, which are angled to match the curve of the blade. They are much more rigid than some of the malleable stylets. Certainly, that increases your risk of potential injury because you're putting something sharper into the airway. That's one of the reasons for recommending trying to stay midline and hugging the laryngoscope device to keep the rigid stylet away from the lateral tissues. Now, I know there are studies ${ }^{1,2}$ looking at the use of regular stylets versus these proprietary stylets, and they found no difference in the rate of success, so I don't think you absolutely need to use the proprietary stylet if you use proper technique. If you use proper technique and you get an ideal view, you should have a fairly easy passage of the tube, even if it you are not using the rigid stylet.

Hagberg: We talk about the different generations of LMAs or SADs [supraglottic airway devices]. Have you seen anything showing a difference in complications with the different types and generations of devices? Also, the different categories: some are more like the LMA, and some are more like the combitube.

Berkow: There's not a huge amount of literature looking at things other than sore throat with SADs. The more serious injuries are just case reports, and there aren't that many. I'm not aware of any literature that says any one particular device is any higher risk than another because it really depends on your cuff pressure, and you can generate fairly high cuff pressures with any of those devices, especially if you choose the wrong size.
Hagberg: I know the earlier studies with combitubes were performed in cadavers, and they found little tears in the esophageal inlet, but I'm not sure about the laryngeal tube, and I personally have not seen anything like that.

Berkow: Right, they're all small case reports. There's really no large series of severe complications with any of the SADs or the video laryngoscopes at this point. They're all individual case reports. I guess they don't get a lot of attention; it's not exciting to publish compared with other things people are looking at.

Collins: We have a subset of patients in the ENT [otolaryngology] population who have had previous injury, particularly vocal cord injury, requiring vocal cord medialization procedures. Aside from not intubating these patients for future procedures if possible, or downsizing an endotracheal tube if intubation is chosen, have there been any other measures that have been looked at or assessed? Do you have any comments about what we can additionally do for those patients?

Berkow: Certainly patients who already come with an injury are potentially at higher risk. By definition, they're high risk to begin with, especially if they have some specific sequelae that lead to their injury. Certainly if you have someone with vocal cord paralysis, and they have a median cord paralysis, potentially putting in a smaller tube can help. There's been debate about whether using an SAD or something that you don't have to put through the glottis itself may be beneficial, but again, the risk of sore throat is still fairly high with an SAD. There's still the potential risk that if you stretch a nerve, you could still have injury; there are pros and cons with each choice. I think you just have to have an extra level of vigilance and try to avoid manipulating the airway unless you absolutely have to. Many of my ENT colleagues have said that if you have a unilateral paralysis, the appropriately sized tube for a short period time shouldn't make that paralysis any worse. If the injury's there, if it's permanent, it's not going to get any better or worse from an acute short-term intubation. There's not a lot of literature out there about different management for patients who already have injury, other than using an appropriately sized tube, shortest duration of intubation possible, and vigilance in care.

Hagberg: I think one thing we really need to make sure to hone in on is multiple intubation attempts, multiple placement attempts of SADs: anything we can do in our practice in order to minimize these types of complications. The best we can do is good technique and not doing the same thing over and over again hoping for better results. If there is failure with a type of device, it may be best to switch to an alternative technique.

Berkow: I totally agree. Almost anything you put into the airway is harder and stiffer than the tissue of the airway. Certainly the more things you put in and the more times you put it in, the higher risk you have for potentially injuring the soft tissue.

Durbin: I noticed a slide where you had the Airtraq device, which has a channel in it and the mirror at the end. I was wondering: these devices were not particularly popular when they first came out. They were disposable, but they were $\$ 100$ a piece. Our emergency room physicians and technicians liked them, but no one else seemed to want to use them. I understand that they now have a non-disposable device, so you could probably afford to use it. I liked the fact that the device has a channel for the tube, so you're not blindly moving the ETT around in the upper airway. We've pretty much adopted the GlideScope approach, but is it time to revisit the Airtraq and 
similar devices with a dedicated ETT channel?

Berkow: There are several video laryngoscopes that have built-in channels: there's the Airtraq, there's the King Vision scope that actually offers you the option of a channeled or unchanneled blade, and then there's the Pentax. The advantage of the channel is that the tube slides alongside the video laryngoscope, so there is potentially less risk of injury, although there's still a blind spot until it comes out. The potential disadvantage that's been discussed about these channeled blades is that you have less freedom of how you introduce the tube. If the tube doesn't go where it's supposed to go, there's no option to manipulate the tube to get it in place. That's the potential disadvantage of a channeled device, but certainly it should decrease the risk of injury to the lateral structures you can't see.

Hagberg: The channeled devices also protect the tube, so what you'll end up finding in a truly difficult airway is that at least you don't have a cuff tear after you finally get the tube in place. That's one of the more protective things about those devices, but I don't think there's a good study that differentiates between channeled versus non-channeled in terms of complication rates. It would be interesting to see.

Berkow: No, there are no studies yet. Again, the case reports on complications with any of these devices have just been coming out in the last $5 \mathrm{y}$ or so. We're not there yet. Hopefully, someone out there is doing a study. The complications are still fairly low, so I think it's going to be difficult to get a large trial of channeled versus unchanneled blades to look for injury. You'd have to do many patients to get enough injuries to compare significance. That's one of the challenges.

\section{REFERENCES}

1. Sakles JC, Kalin L. The effect of stylet choice on the success rate of intubation using the GlideScope video laryngoscopy in the emergency department. Acad Emerg Med 2012;19(2):235-238.

2. Turkstra TP, Harle CC, Armstrong KP, Armstrong PM, Cherry RA, Hoogstra J, Jones PM. The GlideScope-specific rigid stylet and standard malleable stylet are equally effective for GlideScope use. Can J Anaesth 2007;54(11):891-896. 